\title{
UN CHOQUE DE JURISDICCIONES. FUEROS Y POLÍTICA FORESTAL EN EL PIRINEO OCCIDENTAL DURANTE EL SIGLO XVIII
}

\author{
Álvaro Aragón Ruano \\ Universidad del País Vasco-EHU
}

\begin{abstract}
Resumen. La política forestal emanada de la monarquía Hispánica chocó en el Pirineo occidental con un mar de jurisdicciones que dificultaron en extremo su puesta en práctica. En muchos casos, las ordenanzas de montes implementadas en el resto de sus dominios no fueron de aplicación en los territorios forales, que contaron con capitulados específicos, obtenidos tras arduas negociaciones, que cada uno de los territorios, de forma individual, mantuvo con los representantes reales. A través de la presente investigación se pretende analizar el choque de jurisdicciones y marcos legislativos que se produjo entre cada uno de los territorios vasconavarros y las instituciones reales. Debido a sus necesidades forestales en materia naval, la corona «cedió» total o parcialmente, según el caso, ante las presiones forales y jurisdiccionales de cada uno de los territorios vasco-navarros, los cuales lograron importantes ventajas en el ámbito forestal. A cambio, esta obtuvo un mayor control sobre dichos territorios.
\end{abstract}

Palabras clave: País Vasco, Navarra, montes, Marina, conflicto.

\begin{abstract}
The forestry policy from the Spanish Monarchy in Western Pyrenees collided with a multitude of jurisdictions, which extremely challenged its implementation. In many cases, the forest ordinances put in practice in the rest of dominions, weren't applied in foral territories that had specific instructions, gained after arduous negotiations, that each of them held individually with royal representatives. The aim of this research is to analyse the crash of jurisdictions and legal frameworks that took place between the Basque and Navarrese territories and the Royal institutions. Due to its forest needs in naval field, the Crown, in whole or in part, where appropriate, yielded to the foral and jurisdictional pressure of each Basque and
\end{abstract}

Recibido: 26-3-2019 • Aceptado: 17-9-2019 • alvaro.aragon@ehu.es 
Navarrase territories, who acquired important advantages in forestry. In turn, that achieved a higher control over those areas.

Keywords: Basque Country, Navarre, forests, Navy, conflict.

La Real Ordenanza de los Montes de la Marina, de 31 de enero de 1748, y la Real Ordenanza para el aumento y conservación de Montes y Plantíos, de 7 de diciembre de 1748, han sido consideradas como el momento clave de la política forestal española durante el siglo XVIII, siendo objeto de estudio por parte de numerosos autores. A día de hoy queda claro su absoluto fracaso y abandono a partir de la muerte de su principal valedor e impulsor, el marqués de la Ensenada. En líneas generales, la política forestal y las propias Ordenanzas de 1748 adolecieron de importantes improvisaciones, contradicciones e insuficiencias que acabaron por hacerlas inviables. Fueron planteadas como un esfuerzo repoblador y conservacionista de los bosques, pero tuvieron una aplicación despótica, basada en la coacción y el control, lo que las abocó a su fracaso (Aranda y Antón, 1990; Bauer, 1991; Guerra, 1999; Madrazo, 2003; Martínez González, 2015a y 2015b; Pezzi, 2001; Quintero, 2004; Rey Castelao, 1995 y 2004; Torres, 2013; Urteaga, 1987). La reacción contra ellas de las instituciones y comunidades locales no se hizo esperar y adoptó diversas formas: no violenta, traducida en el incumplimiento de las ordenanzas y de las disposiciones de los representantes reales, o manifestada a través de las quejas elevadas a diferentes instancias; o bien violenta, a través de la destrucción de plantíos y de ataques a los representantes de la Marina y la corona (Wing, 2015, pp. 219-222).

Las ordenanzas aludían en su preámbulo al decadente estado de los bosques y estaban dirigidas a distritos y provincias concretos, en los que debían ser ejecutadas, sin tener en cuenta la existencia de privilegios, derechos y costumbres. Todas las tareas de cuidado, vigilancia, reconocimiento, economía y gobierno forestales quedaban sometidas a los intendentes y sus ministros, en el caso de la de 31 de enero, y a los corregidores, en la de 7 de diciembre. En definitiva, las ordenanzas de montes de 1748 pretendieron barrer de un plumazo las jurisdicciones locales sobre el bosque, superponiendo la jurisdicción real y de la Marina a todas las demás (Martínez González, 2014, pp. 589, 590, 599).

No obstante, prácticamente desde un principio, en algunas circunscripciones no tuvieron aplicación, concretamente, en aquellas que contaban con una legislación propia en materia forestal: los territorios forales de Álava, Guipúzcoa, Navarra y Vizcaya ${ }^{1}$.

Galicia es un buen ejemplo de cómo se implementó la Ordenanza de Montes de Marina y de sus efectos, entre los cuales cabe destacar la invasión y expropiación del terreno comunal por parte del Estado y sus ministros (Rey Castelao, 1995, pp. 173 y pp. 192-208, de la misma autora 2004, p. 949). 
Las peculiaridades forestales de los territorios forales, contenidas en sus respectivos ordenamientos y recopilaciones forales, fueron recogidas y confirmadas en diferentes ordenanzas de montes, de forma separada, tratando de adaptarse a la política forestal de los Borbones, pero al mismo tiempo, buscando preservar sus propios usos y costumbres y velar por los intereses de los principales grupos económicos e industriales de dichos territorios. Una vez garantizado el abastecimiento de madera a los arsenales reales, la monarquía no se opuso a reconocer las competencias de los diferentes órganos legislativos y ejecutivos de dichos territorios en materia de control técnico, administrativo y jurisdiccional, funciones que hasta entonces eran compartidas con o ejercidas por los jueces conservadores de montes o por los superintendentes de montes.

La presente investigación pretende profundizar en el choque de jurisdicciones que se produjo a raíz de la aplicación de las mencionadas Reales Ordenanzas de Montes de 1748; en la respuesta de cada uno de los territorios forales y de sus instituciones a la misma; en los debates internos y modificaciones de los capítulos propuestos; y en la evolución de los discursos y de los textos finalmente aprobados y aceptados, ya que son una clara muestra de las tensiones e intereses que en torno al bosque se desarrollaron en estos territorios a lo largo del siglo XVIII — esto es, se intenta analizar el conflicto en un plano meramente jurisdiccional, intra e interinstitucional, dejando para una próxima ocasión el análisis de la conflictividad y el rechazo que su aplicación pudo generar en las comunidades locales, que en este caso nada aporta a los propósitos establecidos - Para ello, además de la importante bibliografía que existe al respecto, hemos echado mano de la documentación y los debates generados en Juntas Generales y Diputaciones de las Provincias Exentas y en las Cortes generales del Reino de Navarra, los cuales se pueden consultar en el Archivo Histórico del Territorio de Álava, el Archivo General de Gipuzkoa, el Archivo General de Navarra y el Archivo Histórico de la Diputación Foral de Bizkaia.

\section{La privativa y omnímoda jurisdicción sobre los montes de Guipúzcoa}

La provincia de Guipúzcoa y sus instituciones trataron, ya desde comienzos del siglo XVIII, de atajar el problema de la deforestación — que se remontaba al menos hasta mediados del siglo XVII - causada por el avance de los cultivos de maíz, el cual provocó nuevas roturaciones a costa del bosque, como lo prueba el establecimiento de un decreto sobre Rozaduras aprobado por las Juntas Generales de Azcoitia en 1657, que se convirtió en el capítulo 5 título 35 de los Fueros de Guipúzcoa y cuyo espíritu quedó reflejado en los capítulos 10, 14 y 15 del reglamento de 1738² (Aragón, 2013;

Archivo General de Gipuzkoa (en adelante AGG-GAO), R 28. 
pp. 46-47; Odriozola, 1997, p. 441). Sobre esta base, las Juntas Generales celebradas en 1718 en Elgoibar iniciaron con ahínco un proyecto para la redacción y establecimiento de un reglamento de montes, creando al efecto una comisión con diferentes expertos para que, una vez evaluado el estado de los plantíos, viveros y zonas baldías de cada una de las repúblicas de la provincia, se estableciesen las disposiciones necesarias para la conservación de los bosques (Registro, 1718, p. 18).

Sin bien la redacción del reglamento de montes de 1738 fue en último término obra de José Manuel de Jaureguiondo y de Diego de Atocha, como bien indican ellos mismos en el preámbulo, ambos tomaron como base los informes y consultas realizados a diferentes expertos: el informe presentado por Antonio de Idiaquez, Juan Bautista de Aranguren y Francisco de Veroiz, en respuesta al requerimiento que se les hizo en las Juntas Generales de 1718; los discursos propuestos con tal motivo por don Antonio de Idiaquez; las noticias que dio don José Miguel de Vildósola; el memorial presentado por don Nicolás de Vicuña y Estensoro en las Juntas Generales de Cestona en 1733; y, finalmente, los discursos que, por encargo de las Juntas Generales de Elgoibar de 1718, de Villafranca de Ordicia de 1727 y de Hernani de 1736, presentó don Miguel de Aramburu (Odriozola, 1997, pp. 439).

La administración real a cargo de José Patiño trató de poner los montes peninsulares en manos del intendente general de Marina y de sus subalternos. Pero en el caso de Guipúzcoa, esto chocaba con su ordenamiento foral, por lo que, coincidiendo con el impase provocado por la desaparición del ministro, las instituciones guipuzcoanas decidieron darle un último y definitivo impulso al reglamento que venían cocinando desde 1718, aprovechando para ello el establecimiento del Almirantazgo en 1737 y la indefinición que de su jurisdicción en materia de montes se mantuvo hasta 1739 (Martínez González, 2014, pp. 576-577, 586). Precisamente, el reglamento de montes de 1738 fue redactado en cumplimiento del decreto establecido en las Juntas Generales celebradas ese mismo año en Deva, y como dejaba caer su mencionado preámbulo:

haziendonos cargo de estos Papeles de las repetidas ordenes del Rey, para que se cuide la plantación de arboles, de la que hemos sabido, que al mismo fin tuvo últimamente de el señor Infante Almirante General, el Comisario Ordenador de Marina don Phelipe de Urioste (Odriozola, 1997, p. 439).

Sin duda, uno de los informes en los que se basaron sus redactores que más llama la atención es el del mencionado don José Miguel de Vildósola, dada la importancia del personaje por aquellas fechas, pues era prior del Consulado de San Sebastián en 1728, cuando se fundó la Real Compañía Guipuzcoana de Caracas, de la que fue uno de sus primeros cinco directores; no obstante, antes de la constitución de dicha compañía, ya había sido el encargado de hacer llegar al puerto y astilleros de Pasajes 
maderas procedentes de todos los rincones de Guipúzcoa y de Navarra, negocio del que también se ocuparía dentro de la Compañía hasta que murió en 1738 (Gárate, 1990, pp. 39, 60, 177, 262, 280).

La carestía de madera que venía padeciendo la provincia de Guipúzcoa, al menos en lo referente a la construcción naval, preocupaba a la Compañía de Caracas, cuyo principal astillero se hallaba en el puerto de Pasajes, por lo que se convirtió en una de las instigadoras de la política proteccionista y de fomento del arbolado. Las Juntas Generales celebradas en Hernani en 1736, a petición de don Domingo Gregorio de Yunibarbia, otro de los directores y representante de la Real Compañía de Caracas - muerto en 1737-, aprobaron un decreto prohibiendo la extracción de madera de Guipúzcoa y otorgaron la preferencia a sus habitantes a la hora de adquirir madera para la construcción y reparación de buques; la Compañía se aseguraba así su disposición para cubrir sus necesidades a unos precios acomodados, eliminando toda competencia externa. Coincidía esto, entre 1735 y 1739, con un período de una aguda crisis de la construcción naval guipuzcoana, a consecuencia de la práctica extinción de los pedidos de la Armada y de los particulares, y a la que sin duda debió contribuir la guerra contra Inglaterra, entre 1739 y 1748 (Alberdi, 2012, pp. 506-507; Odriozola, 1997, p. 122).

La influencia de la Compañía también se dejó sentir en la redacción del reglamento de montes de 1738, donde se incluyeron varios artículos que claramente velaban por sus intereses. El artículo 16 instaba a pedir licencia al Real Consejo de Castilla o a la Real Junta de Almirantazgo para poder disponer de los dividendos que anualmente le correspondiesen a la provincia por sus 100 acciones en la Real Compañía de Caracas, para la financiación de los dos tercios de los censos impuestos para la gratificación o premio de un cuartillo de vellón por cada plantío de más que se realizase por encima de la obligación que le correspondía a cada república (Odriozola, 1997, p. 443). Los artículos 24 y 25 ordenaban fomentar el plantío de nogales en Plasencia y las villas contiguas para, por un lado, evitar la falta de material para las Reales Fábricas $y$, por otro, hacer frente a la demanda de motonería por parte de la construcción naval, actividades en las que la Compañía tenía una importante presencia (Gorosabel, 1899-1901, vol. 3, p. 336; Odriozola, 1997, p. 444). El primero de dichos artículos recogía íntegramente la petición que en las Juntas Generales de Deva de 1738 realizó José Agustín de Zuaznabar, director de la Real Compañía de Caracas y del asiento de las Reales Fábricas de Armas (de Plasencia de las Armas y de Tolosa), del que se hizo cargo la Compañía en 1735 (Registro, 1738, pp. 26-27, 32; Gárate, 1990, pp. 520-533).

La aplicación en Guipúzcoa de la Real Ordenanza de Montes de 1748, concediendo el control de los recursos a las autoridades de la Armada, hubiera supuesto un gran perjuicio para los intereses locales, tanto para los dueños de ferrerías como para la Real Compañía de Caracas, quienes se verían privados de los materiales necesarios 
y a precios adecuados, redundando en mayores costos de producción y menor margen de beneficios para ambas actividad ${ }^{3}$. Efectivamente, los artículos 49 y 50 de la Real Ordenanza de 31 de enero de 1748, que regulaban la extracción de madera a los reales arsenales por los asentistas, prohibiendo su extracción al extranjero, derogaban el mencionado decreto provincial de 1736 (Alberdi, 2012, p. 508).

Por esta razón, la provincia protestó inmediatamente su aplicación y emitió juicio en febrero de 1748 ante las providencias enviadas por el intendente del Departamento del Ferrol para el cumplimiento de la Real Ordenanza de 31 de enero de 1748. Entre otras cuestiones, Guipúzcoa no estaba de acuerdo en que recayese sobre los ministros de Marina la privativa jurisdicción en materia de cuestiones penales relativas a montes, pues ello suponía un contrafuero, ya que según el Fuero, la jurisdicción penal en todos los ámbitos y cuestiones había sido compartida hasta la fecha por las instituciones provinciales, el corregidor y los alcaldes, de forma «acumulativa y a prevención» ${ }^{4}$. Los principales reparos se situaban en torno al papel que debía desempeñar el ministro de Marina, que para la Diputación guipuzcoana debía reducirse exclusivamente a las visitas de montes. A continuación, esta proponía seis artículos — que sirvieron de base a la Ordenanza particular- Solicitaba que el ministro de Marina ejerciese la judicatura de montes con «jurisdicción acumulativa y a prevención» con los poderes provinciales, el corregidor y los alcaldes ordinarios, sin superioridad ni subordinación alguna. No debía haber apelación de una parte a otra, sino que los procedimientos se debían hacer por la vía habitual o ante los tribunales reales por la vía reservada. El juez de montes realizaría una visita general de todos los montes cada dos años, acompañado de una persona capaz nombrada por cada pueblo que visitase. En caso de omisión, negligencia o disimulo, debía dar parte a la provincia para que esta tomase medidas, $y$, en caso de no actuar, al rey por la correspondiente vía. Finalmente, se renunciaba al cumplimiento de la petición de licencia ante el juez de montes para marcar, señalar o acotar árboles que pudiesen servir para la fábrica de navíos ${ }^{5}$ (Aragón, 2001a, p. 197).

\footnotetext{
Algo similar ocurrió, por ejemplo, en Castilla, donde la ordenanza damnificó a ayuntamientos y campesinos, que se quejaban de tener que acotar al ganado los espacios plantados durante seis años y de la dificultad de encontrar espacios donde aplicar los plantíos, dado el férreo control impuesto por los ganaderos y la creciente demanda que sobre el terrazgo dedicado a cereal impuso la presión demográfica. En respuesta, utilizaron muy diversos medios para burlar el celo de los corregidores, recurriendo a cambiar de lugar los árboles ya prendidos, a anotarlos como nuevas plantaciones o a falsear las estadísticas de plantíos - prácticas así mismo habituales en el caso guipuzcoano o vizcaíno- (Guerra, 1999, pp. 60-65). Casi una década después de su aprobación, las autoridades reales denunciaban el poco celo mostrado en su aplicación por justicias locales, corregidores y campesinado castellanos (Madrazo, 2003, p. 59).

«Jurisdicción acumulativa» es aquella por la cual puede un juez conocer de las mismas causas que otro, y «a prevención» aquella por la que un juez conoce de una causa con exclusión de otros que son igualmente competentes, por habérseles anticipado en su conocimiento.

AGG-GAO, JD IM 2/17/36.
} 
La Ordenanza particular de los montes y plantíos de Guipúzcoa, concedida el 28 de junio de 1749, fue la respuesta a los perjuicios que recibiría el territorio de aplicarse literalmente la Ordenanza de Montes de Marina del 31 de enero de 1748. Dicha Ordenanza particular, mandaba que Guipúzcoa conservase la jurisdicción que hasta el presente había ejercido sobre los montes de su territorio, dando por sí y en su nombre todas las providencias y órdenes económicas - esto es importante, recalcarlo_- respetando el título 38 de sus Fueros y el Reglamento de 1738. Las instituciones provinciales debían velar por la total conservación de sus montes, nombrando personas para el cuidado y castigo de las negligencias. El ministro de Marina podía visitar cada dos años los montes del territorio, para comprobar si la ordenanza se estaba cumpliendo. Cuando decidiese hacer la visita, debía pasar aviso a la Diputación, que señalaría un sujeto que le acompañase o expidiera a las repúblicas las órdenes necesarias. Los montes particulares se regían por las mismas reglas, en lo relativo a cortas y visitas del ministro. Por fin, la Diputación determinaría por sí misma todas las dudas y competencias sobre plantíos y conservación de montes, pudiéndose recurrir al ministro de Marina, quien remitiría los autos a la Diputación para que hiciese justicia, y en caso de omisión, daría cuenta al rey por medio del Secretario del Despacho de la Marina. En cuanto a los pleitos que se suscitasen sobre pertenencia y extensión de montes, se seguiría la costumbre desarrollada hasta la fecha, con las apelaciones regulares a los tribunales correspondientes, sin intervención de la jurisdicción de Marina (Gorosabel, 1899-1901, vol. 3, pp. 337-338; Novísima Recopilación, 1975, pp. 548-552).

Hay que recordar, que gracias a la Ordenanza de 31 de enero de 1748 en el resto de territorios de la corona los intendentes - tal como había propuesto en 1735 el intendente de Ferrol - se hicieron con las funciones de los jueces de montes, y que en 1751 se ordenó que hubiese un ministro de Marina en cada partido, sometido a los primeros, quedando el resto de justicias obligadas a aportar información a los visitadores y a hacer cumplir sus autos, pudiendo estos aplicarlos de manera sumaria, al margen de la justicia ordinaria, estableciéndose la posibilidad de elevar las apelaciones ante el intendente — en el caso gallego, le correspondía al de Ferroly, en última instancia, ante el secretario del Despacho de Marina (Rey Castelao, 1995, pp. 173-177).

A fin de garantizar el cumplimiento de lo establecido en el capítulo 11, la provincia nombró una comisión que se reunió y negoció con el ministro de Marina, Manuel de las Casas, el 24 de agosto, seis capítulos «adicionados» que fueron aceptados por Real Orden de 1 de septiembre de 1749 y, posteriormente, modificados y actualizados por Real Orden el 9 de abril de 1783. Ante lo difícil de la orografía y debido al carácter disperso del poblamiento en Guipúzcoa, se estableció que no fuese necesaria en 
cada ocasión la petición de licencia de corte ante el ministro de Marina, residente en San Sebastián, si bien deberían respetarse una serie de limitaciones —esta cuestión se repitió en el caso de Navarra y Vizcaya - En primer lugar, no se podrían cortar árboles marcados para la Real Armada sin la expresa licencia del ministro de Marina. En segundo lugar, las justicias locales deberían velar porque sus vecinos no cortasen árboles que en el presente o en el futuro pudiesen servir para la construcción de bajeles reales, aunque no estuviesen marcados al efecto, debiendo dar noticia a la provincia y al ministro 6 (Aragón, 2001a, p. 178; Gorosabel, 1899-1901, vol. 3, pp. 338-340; Novísima Recopilación, 1975, pp. 552-553).

En realidad, como se ha podido comprobar, ni en la Ordenanza particular de 28 de junio de 1749 ni en los capítulos «adicionados» de 1 de septiembre de 1749 se establecía expresamente que correspondiese a Guipúzcoa la «privativa jurisdicción», sino que el capítulo 24 establecía que esta determinaría por sí misma todas las dudas y competencias sobre plantíos y conservación de montes. En efecto, si bien en escasos meses la Diputación pasó de reclamar la «jurisdicción acumulativa y a prevención», a exigir la «jurisdicción privativa», el camino hacia esta última fue largo y se puede situar entre 1749 y 1790. De hecho, como reconocía la Ordenanza de Montes de 1825, Guipúzcoa hacía uso de la autoridad que le concedían sus fueros «y de la jurisdicción privativa, y omnímoda que me compete según el artículo 24 de la Real Cédula de 28 de junio de 1749 y Reales órdenes de 2 de marzo de 1773 y 24 de mayo de 1790 [para que], se formen en el juzgado de mi Diputado General las correspondientes causas de oficio y se castigue a los delincuentes como lo prescriben las leyes ${ }^{7}$. Ante lo equívoco del texto original de 1749, las instituciones guipuzcoanas se vieron obligadas a buscar la definitiva confirmación de esa privativa y omnímoda jurisdicción, y aunque posteriormente los enfrentamientos se siguieron reproduciendo, fueron de menor intensidad. Por tanto, fue a partir de 1790, y no antes, cuando la Diputación guipuzcoana comenzó a sustanciar de forma regular las causas de montes, pues hasta 1749 había sido el corregidor quién se ocupaba de la mayor parte de ellas, sin intervención directa de aquella, en virtud de la «jurisdicción acumulativa y a prevención» que, como se manifestaba en el juicio emitido en febrero de 1748, compartieron hasta entonces la provincia, el corregidor y los alcaldes ordinarios, con apelación ante el tribunal del corregidor y de la Real Chancillería de Valladolid. En realidad, fue la Ordenanza de Montes de Marina de 31 de enero de 1748 la que concedía la privativa jurisdicción a los intendentes de Marina, lo que generó la reclamación de Guipúzcoa, que supo ingeniárselas para revertir la situación y derivar dicha privativa

Archivo Histórico de la Diputación Foral de Bizkaia (en adelante AHDFB), AJ00010/006.

Archivo Municipal de Zumárraga, E/2/III/1/6. 
jurisdicción, que nunca había detentado, hacia sí misma, sustituyendo en su papel a los intendentes de Marina. Guipúzcoa reclamó abiertamente a partir de 1767 la privativa y omnímoda jurisdicción y la corona comenzó a reconocerla y confirmarla. Cabe recordar que un año antes, la Real Compañía de Caracas había recibido el asiento de provisión de maderas para los reales arsenales, lo cual sin duda debió influir en la decisión de la corona, y que entre 1750 y 1770 el sector siderúrgico experimentó un período de recuperación y alza, que tuvo como principal acicate la demanda de la Armada (Aragón, 2001a, pp. 166-172; 2001b, pp. 45-55; Gorosabel, 1899-1901, vol. 3, pp. 342-345; Carrión Arregui, 1991, p. 283).

De todas formas, tras esa grandilocuente expresión, existía una realidad mucho más limitada, puesto que la Diputación únicamente se encargó de las causas entre concejos y entre estos y particulares. Precisamente, el 15 de diciembre de 1791, tras la última confirmación real de la mencionada jurisdicción, el consultor de la provincia, Ramón María de Moya, envió un dictamen con las reglas para simplificar las causas criminales sobre excesos en el corte de montes, a fin de agilizar los procesos, ventilando las causas a instancia de un concejo o particular, con apelación al Consejo de Guerra, y las de oficio, a instancia de la Diputación, en un plazo de 15 o 20 días, de forma que las causas con daños superiores a 1.000 reales se tramitaban en la Diputación, mientras que las menores a dicha cantidad se veían ante los alcaldes. Es decir, la Diputación se reservaba para sí las causas donde los daños eran mayores, sin duda, con dos propósitos: establecer castigos ejemplares y garantizarse los mayores ingresos y penas — como se verá, esto también ocurrió en el caso de Álava—. De hecho, la totalidad de los pleitos surgidos entre 1791 y 1805 , en los que estaban implicados varios concejos o un concejo y particulares, fueron substanciados ante el tribunal de la Diputación, mientras el corregidor siguió viendo causas entre particulares, además de las civiles (Aragón, 2001b, pp. 56-59).

Gracias a la Ordenanza particular, las necesidades de la industria siderúrgica y de la Real Compañía de Caracas quedaron aseguradas. Es más, en lo sucesivo la Compañía de Caracas no sólo no se opuso a la extracción de las maderas guipuzcoanas hacia los reales arsenales, sino que incluso participó en ella. Por un lado, formalizó asientos con particulares a fin de que le proveyesen de la madera adecuada para la construcción de sus navíos, y, por otro, firmó en 1766 el mencionado asiento para proveer a la Real Armada de madera procedente del Pirineo navarro y de los montes guipuzcoanos (Alberdi, 2012, pp. 824, 1978, 1079; Aragón, 2001b, p. 56; 2017, pp. 41-53). 


\section{2. «Que la Diputacion general haya de entender gubernativa y económicamente en los negocios de los dichos montes, y el corregidor en lo contencioso». El largo peregrinar de Vizcaya}

El señorío de Vizcaya, por su parte, permaneció atento a su provincia hermana, Guipúzcoa. A diferencia de esta, en Vizcaya, en un primer momento, la Ordenanza de Montes de la Marina de 31 de enero de 1748 fue plenamente asumida y puesta en práctica. Pero posiblemente el ejemplo del vecino territorio movió a las autoridades vizcaínas a plantear sus propias demandas. En respuesta a la Real Orden de 1748, Vizcaya aseguraba no precisar de ministro de Marina, pues ya tenía juez privativo conservador superintendente de montes, elegido por la propia corona, con «omnimoda privativa jurisdiccion, que practica todos los años su visita con facultad de multar, castigar y mandar hazer viveros con lo que pareze de mas el nombramiento del Comisario de Marina que se opone a los fueros». Las alegaciones, de forma similar a Guipúzcoa, se centraban en el perjuicio a las ferrerías, pues privándose a los ferrones de la libertad de cortar por el pie los árboles infructíferos y obligándoles a llevar un perito al corte - aumentando considerablemente los costes - , no tendría el señorío de Vizcaya hierro, a cambio del cual introducir trigo y maíz, ni curvatones para los reales bajeles. El 27 de diciembre de 1749 llegó a Lanestosa Francisco Antonio de Ravago y los Ríos, comisario de Marina, nombrado visitador en las villas de la Costa de Cantabria, asistido por Juan Francisco Sánchez Duque, como escribano, requiriendo al alcalde de la mencionada villa vizcaína el cumplimiento de la Real Orden de Montes. En respuesta, en enero de 1750 el señorío de Vizcaya solicitaba que la Ordenanza de Montes no fuese de aplicación en su territorio y se siguiesen aplicando la ley 8 del título 1 y la ley 4 del título 24 del Fuero ${ }^{8}$. Curiosamente, fue el propio marqués de la Ensenada, consciente del malestar del señorío, quién el 2 de febrero de 1750 remitió a este una carta orden con la Real Cédula de 28 de junio de 1749, que contenía la Ordenanza particular establecida por Guipúzcoa para el plantío y conservación de sus montes, a fin de que fuese examinada. En nuevas cartas órdenes, Ensenada enviaba las seis reglas adicionales concertadas con Guipúzcoa, por si pudiesen servir de ejemplo ( 2 de febrero de 1750), aceptaba que el asunto se viese en la siguiente Junta General del señorío de Vizcaya (2 de marzo de 1750), y solicitaba que se le notificase lo acordado (20 de julio de 1750).

La Junta General reaccionó a esta última misiva acordando el propio 20 de julio de 1750 nombrar una comisión que debía reunirse con los señores consultores para

La Ley 8 del título 1, se inicia con un «por quanto todos los Montes, usas, y exidos son de los hijosdalgo e pueblos de Vizcaya». Por su parte, la ley 4 del título 24, «Que habían de Fuero, y establecían por Ley, que por quanto los exidos, y usas de Vizcaya, son de los hijosdalgo de ella». 
reconocer la Real Orden, reales órdenes y reglas establecidas por Guipúzcoa y exponer sus dictámenes e informar a la Junta de lo más adecuado. Transcurridos dos días, es decir, el 22 de julio de 1750, se presentó en dicha Junta una ordenanza alternativa, compuesta por 16 artículos, que debería ser enviada al monarca para su sanción — si bien finalmente fue desechada y modificada en 1752 - como así se hizo, aunque no recibió respuesta. En el preámbulo de dicha propuesta se dejaba claro que la intención de la misma no era otra que garantizar el buen estado de los montes de Vizcaya, tanto concejiles como particulares, y el pasto de los ganados, para atender al mismo tiempo a las demandas de la Armada Real, de la marina mercante y de la industria siderúrgica del señorío9. El 27 de julio dicho señorío de Vizcaya envió a Ensenada los artículos proyectados. Lo más destacable del mencionado texto, en lo que se refiere al tema aquí tratado, es decir, a lo jurisdiccional, es que el capítulo 15 establecía que el asunto de montes competía, en el ámbito de las dos leguas al mar, al juez superintendente de montes, mientras que en el resto del territorio, a las justicias de los pueblos, con subordinación y apelación al corregidor, procediendo este en lo contencioso, mientras que «por lo que mira a lo politico, economico y gubernativo entendera y conozera la Diputacion General y sucesibamente la Junta General», a excepción de las Encartaciones, dónde debía entender la Junta de Avellaneda, con los recursos de fuero al corregidor y diputados generales ${ }^{10}$.

La Diputación celebrada el 9 de enero de 1751 recordaba el silencio del monarca, a pesar de lo cual dio orden de que se cumpliera la ordenanza, considerando que se acercaba el tiempo de siembra de viveros y la plantación de quejigos. Dicha ordenanza rectificaba lo dispuesto por la Real Ordenanza de Montes de 1748 sobre las competencias del ministro de Marina, a quien se reservaron únicamente las visitas a los montes cada dos años, quedando para las autoridades forales vizcaínas la jurisdicción política, económica y gubernativa, cediendo - a diferencia de Guipúzcoa - la jurisdicción contenciosa al corregidor. Finalmente, la Real Orden de 17 de abril de 1752 instaba al señorío de Vizcaya a que «formase reglas adaptadas a su constitución con cuia practica se poblasen y mantuviesen poblados sus montes y exidos», poniendo en conocimiento de las autoridades de Vizcaya que en adelante la jurisdicción gubernativa y económica del ramo recaería enteramente en el señorío y sus instituciones. Los ministros de Marina quedaban, por tanto, relegados a la inspección y periódicas visitas de los montes, a fin de conocer su estado, advertir al señorío de los excesos y la falta de aplicación e informar de ello al monarca. En este caso, también se formó una comisión, compuesta por el mismo equipo que estableció los anteriores 16 capítulos, que los días 6, 7, 8 y 
9 de junio negoció con los poderhabientes de Bilbao el establecimiento de los medios más proporcionados y reglas adaptables a la Ordenanza de montes de 1748, debiendo llevar al día siguiente un dictamen para resolverlo.

Sin embargo, su aprobación en las propias Juntas no estuvo exenta de conflictos. Don Antonio de Larrinaga y Arteaga, como sustituto y apoderado del superintendente de montes del señorío de Vizcaya, protestó porque según él la superintendencia no quedaba excluida en la Real Orden de 17 de abril, ante lo que el síndico general, Juan de Dudagoitia, le pidió que se abstuviese de ejercer dicho cargo. Por su parte, el señor Don Manuel de Salazar y Salamanca, síndico de las Encartaciones protestó y reclamó que lo económico, gubernativo y contencioso en el caso de las Encartaciones debía corresponder a las justicias de su distrito y su Junta de Avellaneda, a lo cual Juan de Dudagoitia se negó ${ }^{11}$. Nuevas protestas se produjeron en la siguiente Junta, una vez más a cargo de Antonio de Larrinaga, en nombre del marqués de Villarreal, superintendente de montes. En consecuencia, se suplicó a Ensenada que ordenase al mencionado superintendente que se abstuviese de continuar con sus protestas y cometido, quedando su labor y cargo reservados exclusivamente para la Diputación. A consecuencia de estos debates, el texto original, establecido el 22 de julio de 1750, fue modificado y se le añadieron una serie de correcciones, denominadas «adicciones», el 9 de junio de 1752.

La principal modificación fue que el artículo 15 relativo a la jurisdicción quedaba sin fuerza, mandando que la «jurisdiccion gubernativa y económica [...] resida enteramente en el Señorio, y la contenciosa en el Señor corregidor y sus sucesores, quedando el caballero Ministro de Marina solamente al cuidado de visitar los Montes para informar al rey o advertir al Señorio de excesos». Quedaba, por tanto, suprimida la superintendencia y la jurisdicción de la Junta de Avellaneda, en lo relativo a las Encartaciones, que pasaban a dominio de las autoridades del señorío de Vizcaya, y exentas las villas de los gastos ocasionados por las visitas a los montes. Sobre la Ordenanza de montes, se aprobaron las 17 reglas — pues se había añadido un capítulo referente al régimen de podas - y se decidió remitirlas con copia íntegra al rey, junto a las adicciones del 9 de junio de $1752^{12}$. Tampoco en esta ocasión se obtuvo la aprobación real, al menos no de forma inmediata, pues tuvieron que pasar más de tres décadas para que la Ordenanza fuese confirmada, merced a la Real Orden del 27 de noviembre

11 Los conflictos jurisdiccionales entre el señorío de Vizcaya y las Encartaciones fueron intensos entre 1720 y 1770. La resistencia de las Encartaciones fue más tenaz ante el intento, a lo largo del siglo XVIII, de las Juntas de Guernica y la Diputación de adquirir una posición directiva sobre el resto de corporaciones que componían territorialmente el mencionado señorío (Martínez Rueda, 2008, pp. 239-243).

12 AHDFB, AJ00488/002, pp. 16-18, y pp. 21-33; AHDFB, AJ00010/006, ff. 328-337 r; Archivo Municipal de Areatza, 0010/006/016. 
de 1784, incluida en los acuerdos de las Juntas Generales de julio de $1786^{13}$ (Portillo, 1991, pp. 413-421; Uriarte, 1988, pp. 100-107; Novísima Recopilación, 1805, p. 553).

\section{3. Álava: de la aceptación inicial a la obtención de la jurisdicción contenciosa}

La provincia de Álava no quedaba dentro de la circunscripción de la Real Ordenanza de Montes de la Marina de 31 de enero de 1748, al hallarse más allá de la distancia de veinticinco leguas con respecto al mar, por lo que esta no fue de aplicación, y sí la Real Ordenanza para el aumento y conservación de Montes y Plantíos de 7 de diciembre de 1748, cuya publicación comunicó a las Juntas Generales el diputado general de Álava, José Ignacio de Álava y Arista, el 12 de diciembre de ese mismo año. En realidad, la provincia de Álava tenía su propio régimen en lo relativo a la conservación de sus montes que, básicamente, estaba en manos de sus municipios y villas, los cuales gestionaban todo lo relativo a ese ramo a través de sus ordenanzas municipales. De hecho, la provincia de Álava ya venía desarrollando desde comienzos del siglo XVIII una política de repoblación y plantíos para el mantenimiento de su riqueza forestal, estableciendo la obligación de los pueblos de remitir anualmente a las Juntas, en el mes de marzo, los testimonios de siembra de bellotas y plantíos ${ }^{14}$.

Los conflictos jurisdiccionales, sin embargo, fueron ya anteriores al establecimiento de las ordenanzas de 1748. Así en 1746 las Juntas Generales otorgaban poder al diputado general para comunicar al marqués de Montehermoso que entregase y no hiciese uso del despacho con su nombramiento como superintendente de montes y plantíos, por ir en contra de los privilegios de la provincia; en caso de no lograrlo, se instaría al agente en Corte para que siguiese con la gestión ${ }^{15}$. En abril de 1749 se leyó el despacho expedido el 12 de diciembre de 1748 con los 39 capítulos sobre plantíos y ejidos, enviado por José Bermúdez, miembro del Consejo Real, encargando su ejecución y cumplimiento. Ante este requerimiento, se acordó formar una comisión para que, junto al consultor de la provincia, redactase un reglamento a fin de poner en práctica algunos de los aspectos prevenidos en los capítulos del despacho real, «mirando y atendiendo a que en manera alguna se perjudique al dominio que en sus propios montes corresponde a dicha prouinzia según sus fueros y priuilegios y que hecho y formado dicho arreglamento lo exiuan y manifiesten para determinar en el asumpto todo aquello que fuese mas vtil» ${ }^{16}$. Días después se acordó insertar en el libro

AHDFB, AJ00393/001; AHDFB, AJ00005/012.

Archivo del Territorio Histórico de Álava (en adelante ATHA), legajo 26, ff. 86 r y v.

ATHA, legajo 26, ff. $248 \mathrm{v}$.

ATHA, legajo 34, ff. 84 v. 
de decretos el mencionado despacho real y comunicar a Bermúdez los privilegios de la provincia en este sentido y la aplicación de la misma en lo que competía a dicha conservación, por no ir contra sus privilegios. No obstante, si bien se aceptaba la Real Orden, se hacía con matices, pidiendo que:

se satisfaga a dicho señor don José Bermudez diziendole la diferencia con que esta Prouincia deue contemplarse de las demás en el asumpto por la especialidad que desde el tiempo en que entrego voluntariamente al señor rey Don Alonso el onzeno de gloriosa memoria reseruo en si y le fue conzedida sobre la propiedad y dominio de los montes y pastos públicos que gozaua antes de la entrega y siendo señora de si misma, bajo de cuio concepto ni al Honrado Concejo de la Mesta se permite la liuertad que por sus leies y estatutos como por las de el reino le están conzedidas y que de paso se le signifique el sumo cuidado y aplicación con que la prouincia procura a la conservazion de sus montes repitiendo las prouidenzias y acuerdos mas estrechas y respectiuas a que se hagan plantios y que no se corte en los montes a liuertad de los vecinos ni de otra suerte (Cuaderno de Leyes, 1825, pp. 297-299) ${ }^{17}$.

Prácticamente un año después, en mayo de 1750 comenzaron los conflictos y debates internos dentro de la provincia. Las Juntas de Elorriaga y Lasarte, jurisdicción de la ciudad de Vitoria, se quejaban de que a pesar de que el diputado general había enviado a los pueblos la Ordenanza de 7 de diciembre de 1748, sin imponer, no obstante, novedad a los tradicionales usos y costumbres, la ciudad de Vitoria había querido ejecutar literalmente la ordenanza, restringiendo a sus aldeas el uso de los montes comunales, transgrediendo de esa forma anteriores ejecutorias y privilegios de los que disfrutaban dichos lugares para la libertad de corte. Por su parte, el cura párroco de Espejo se quejaba de que los pueblos circundantes no le permitían el corte de pinos en los montes de Pinedo, Corro o Tobillas. Finalmente, Salinas de Añana, que alegaba producir 40-50.000 fanegas de sal anuales ${ }^{18}$, para lo que compraba madera procedente de las comunidades del entorno, se quejaba de que estas ahora no le querían vender, en aplicación de la Real Ordenanza. Las Juntas Generales de la provincia se vieron en la obligación de establecer un acuerdo para que los montes de ella se disfrutasen, según se había hecho hasta la fecha, conforme a la costumbre y ordenanzas de los pueblos y hermandades, sin tener que solicitar licencia a las justicias ordinarias para la extracción de materiales de los mismos, ni para su venta a aquellos forasteros que los necesitasen en los precios en que se ajustasen, procurando la conservación y aumento de dichos montes ${ }^{19}$ (Cuaderno de leyes, 1825, pp. 302-305).

ATHA, legajo 34, ff. $90 \mathrm{v}-91 \mathrm{r}$.

Cifras que coinciden con las aportadas por Porres Marijuán, 2007, p. 192.

ATHA, legajo 34, ff. 130v-134v. 
En el año 1756 hubo un intento, fallido por otra parte, para establecer un reglamento de ferrerías y fomento de la repoblación forestal y conservación de montes. El texto, confeccionado por una comisión creada en mayo de ese mismo año para concertar con los dueños de las ferrerías de Villarreal, La Encontrada y Abornícano su compra y desmantelamiento o conversión en fraguas, contenía catorce capítulos para la conservación y aumento de los montes de Álava, en relación a la creación de viveros, repoblación forestal, usufructo de árboles frutales, limpieza de montes, fomento de árboles frutales, forma de realizar los plantíos de robles y castaños, difusión de las ordenanzas junto a las «Reglas y observaciones para la administración y gobierno de los montes de Vizcaya», libro tercero de la obra de Bernardo Villarreal de Bérriz (1736), programación de una inspección por el diputado general durante el trienio de su mandato, corriendo con los gastos de la misma los pueblos que incumplieran la normativa, o en su defecto la provincia, y estableciendo un periodo anual de 15 días para su realización — siendo este último el aspecto más controvertido-.

Mostraron su oposición a dichas reglas el procurador general de Aspárrena, mientras que se adhirieron los de San Millán y suspendieron su voto los procuradores de Zuya, Cuartango, Urcabustaiz y Villarreal, hasta consultarlo en sus municipios. Esta cuestión provocó fracturas internas dentro de las instituciones provinciales, puesto que los procuradores de Salvatierra y Ayala reclamaron que el ramo de montes era competencia de las justicias ordinarias de cada lugar y no del diputado general, quien se estaba arrogando un poder jurisdiccional que no le correspondía. Salvatierra se mostró favorable a que la conservación de montes y la repoblación forestal fuesen una competencia de la justicia ordinaria, tal y como había sido hasta la fecha, según lo avalaban ciertas leyes del Cuaderno, oponiéndose además a la construcción de ferrerías, por lo que estaba de acuerdo con que se desmantelasen las existentes, por haber incumplido la normativa, y con que en adelante no se concediesen más licencias. Ayala, por su parte, se mostró contrario a que fuese el diputado general quien llevase a cabo la visita de inspección de los montes de la provincia, proponiendo que para evitar costas la hiciesen los procuradores de cada hermandad o los regidores de cada concejo. Pedía que fuesen sus procuradores generales los que ordenasen a los regidores que se encargasen de las visitas, llevando luego testimonio a las Juntas Generales.

La Hermandad de Salvatierra pidió que se tuviese en cuenta el capítulo 13 de la voluntaria entrega de 1332 — que otorgaba los montes de la provincia a sus hidalgos - y la ordenanza cuarta del cuaderno de leyes de la provincia, donde se establecía en qué casos debía entender la provincia, de donde se colegía que:

esta dicha Probinzia ni su Junta no tienen autoridad ni facultad alguna para hazer ordenanzas poner leies ni tomar otra prouidenzia alguna en razón del establecimiento de montes, siembra de semillas para ello ni sus cortes y talas por deuer cuidar como 
asta aquí se a ejecutado todo el cuidado de las justicias ordinarias cada una por lo tocante a su territorio a quien siempre se an dirijido y cometido las ordenes zedulas y despachos expedidos por Su Magestad ${ }^{20}$.

En caso de aplicarse, continuaba la mencionada Hermandad, habría muchos debates y disensiones entre el diputado y las justicias locales. En cuanto a las ferrerías, tampoco las Juntas Generales tuvieron nunca poder para dar licencia de apertura, sino que era cada hermandad la que la concedía, pidiendo que en adelante no se permitiese levantar ninguna nueva ferrería. Ante el acalorado debate y la falta de consenso, finalmente, los capitulares de las Juntas Generales tomaron la determinación de suspender las ordenanzas y de que los pueblos se siguiesen rigiendo por sus costumbres y ordenanzas, sin que el diputado general o las Juntas Generales pudiesen inmiscuirse en el asunto ${ }^{21}$.

La cuestión no volvió a estar en la agenda de las instituciones provinciales hasta comienzos de la década de los años ochenta, cuando el avance de la agricultura, las necesidades de la Real Armada y de otras actividades industriales, entre las que estaba la extracción de cortezas para el curtido y confección de calzado - común también a las provincias de Vizcaya y Guipúzcoa (Aragón, 2001a, pp. 63-64, 118) —, además del consumo de madera por parte de la ciudad de Vitoria, encendieron las voces de alarma $^{22}$. Las Juntas Generales se vieron obligadas a establecer en mayo de 1779, en el marco de la guerra con Inglaterra, un acuerdo para que las justicias ordinarias hiciesen las diligencias oportunas a fin de perseguir la extracción ilegal de cortezas de robles y el cumplimiento de las ordenanzas, a pesar de lo cual todavía en 1786 los procuradores generales de Cuartango, Tierras del Conde de Salinas y Lacozmonte se seguían quejando de dichos daños ${ }^{23}$.

En mayo de 1784 las Juntas Generales adoptaron un acuerdo para que las justicias ordinarias averiguasen si se habían cometido excesos en la tala de árboles por parte de algunas hermandades, movidas por el temor de que los árboles fuesen marcados por el ingeniero de Marina para la construcción de barcos, ante la baja tasación dada por el mismo. Las Juntas Generales se vieron obligadas a decretar el sobreseimiento de las cortas que se estaban realizando hasta que la Junta del Departamento de Ferrol comunicase el número exacto de maderas que necesitaba. Se permitía la visita y vista de los árboles, pero no su marcado. Es en ese contexto, en el que las instituciones pro-

20 La mencionada ley cuarta decretaba el establecimiento de siete alcaldes de Hermandad, que eran los que debían conocer sobre los cinco casos de robos, fuerzas, talas, cortas y acechanzas (Cuaderno de Leyes, 1825, pp. 75 y 91).

21 ATHA, legajo 36, ff. 7v-11v, 23r-24v. Sobre las ferrerías en Álava, véase Rodríguez, 2014, pp. 465-499.

22 Al respecto de la economía alavesa en el siglo XVIII y su expansión entre 1720 y 1780, Bilbao, 1996.

23 ATHA, legajo 44, ff. 6v-7r y legajo 47, ff. 120v-121r. 
vinciales se plantearon establecer un reglamento propio y actualizado para el cuidado y conservación de montes, repoblaciones de árboles y frutales, que fue aprobado el 11 de julio de $1784^{24}$. Algunos de sus capítulos hubieron de ser enmendados posteriormente, en $1785^{25}$. No obstante, el reglamento de montes no obtuvo la sanción real inmediatamente, por lo que entre 1789 y 1792 se revalidó anualmente la comisión dada al diputado general para solicitarla. Finalmente, el diputado general informaba que la ordenanza o reglamento de montes, enviada el 26 de noviembre de 1791, había sido aprobada por el Consejo Real el 24 de septiembre de 1793, siendo su principal medida, en lo jurisdiccional, que correspondían a las justicias locales o alcaldes ordinarios aquellas penas que no excediesen los 20 ducados, mientras que para el diputado general, en vez del corregidor — como preveía dicha Real Ordenanza de 1748-, quedaban aquellas que excediesen dicha pena, lo cual nos acerca nuevamente al caso de Guipúzcoa. En realidad, la confirmación del reglamento se concedió dentro de un pleito elevado por los vecinos de la villa de Andollu y del lugar de Oreitia contra Juan Bautista Porcel y Cañaveral, señor de la primera, por el corte de una serie de árboles en el monte de Arambalza. Lo interesante del proceso es que en sentencia de 28 de enero de 1789 el diputado general fue declarado juez incompetente. No obstante, los concejos volvieron a apelar ante el Consejo de Castilla y finalmente una Real Orden de 12 de noviembre de 1793 sentenciaba a su favor y ratificaba el reglamento formado por la provincia, confirmando la jurisdicción del diputado general en los términos ya descritos $^{26}$ (Cuaderno de Leyes, 1825, pp. 307-327).

Según Garayo Urruela (1991, p. 18) con el Reglamento para el cuidado y conservación de montes y frutales, se implantó la fiscalización técnico-administrativa de los cortes del arbolado y, como ocurría ya en Guipúzcoa, el diputado general, en cuanto juez y subdelegado de montes de Álava, se convirtió en la suprema jurisdicción y autoridad penal. Esto sirvió de base legal para la abolición de la libertad vecinal de corta, la rebaja de atribuciones en las competencias jurisdiccionales de órganos personales y colectivos y, en definitiva, para la injerencia de poderes externos en la vida organizativa y productiva de las comunidades rurales.

\section{Navarra, la jurisdicción gubernativa y económica y el juez de montes}

La legislación forestal de Navarra no fue profusa ni sistemática, hasta que a partir del siglo XVIII las medidas comenzaron a acumularse. Así la ley 1 de 1709 y

ATHA, legajo 46, ff. 149v-150r, 153v-154r, 172r y v, y legajo 47, ff. 3r-4v; DAH, FCAU, 001-040. ATHA, legajo 47, ff. 63v-64r.

ATHA, DH, 4391-7, 32 ff.; legajo 49, ff. 25v-26r, 147r, 179v; legajo 50, f. 43r; legajo 51, ff. 94v$96 \mathrm{v}$. 
la ley 10 de 1724 establecían que ni para el servicio de la Real Armada se pudiesen cortar árboles sin preceder aviso a los pueblos y señalamiento en los parajes menos perjudiciales. Así mismo, la ley 11 , título 15 , libro $1^{\circ}$ respetaba la extracción de madera a Guipúzcoa y otros territorios, siempre y cuando fuese registrada y declarada en la última tabla o aduana. Sin embargo, esas medidas y prevenciones no se respetaban y, ante los excesos, las Cortes de 1724 se vieron obligadas a establecer la ley 57 por la que ninguna comunidad ni particular pudiese extraer a Francia leña, carbón, tablas, remos, ni maderas, bajo pena de 500 libras (Fortún, 1995, Libro 7, p. 54). Sin embargo, en el Real Decreto establecido, la corona introducía una variante de importancia, pues consideraba que tales medidas de nada servirían si no «se destina Ministro de toda integridad, que con el título de Juez conservador de montes, y plantios conozca en primera instancia de todas estas causas y de tres años en tres años visite los montes y plantios para que se haga observar y cumplir todo», para lo que ordenaba al virrey su nombramiento, con privativa jurisdicción y apelación al Consejo de Guerra, como establecían las Ordenanzas e Intrucciones Generales para el cuerpo del Ministerio de Marina de 1725, que concedían plenos poderes en materia forestal al intendente general de Marina y a los intendentes particulares, a quienes se facultaba en todo lo relativo a economía, policía, real hacienda y apresto de navíos, así como para la administración de justicia «civil y criminal» de todos los asuntos de su competencia (Martínez González, 2014, pp. 573-575).

La respuesta de las Cortes, ante esta injerencia, fue por supuesto inmediata y en la primera réplica rechazaban el establecimiento de un juez conservador, considerando que semejante tarea no podía depender de una sola persona, siendo más eficaz la actuación de los alcaldes y regidores de los pueblos. Uno de los principales inconvenientes - coincidiendo en el argumento con el que posteriormente utilizarían Guipúzcoa y Vizcaya - , era que de establecerse dicho juez conservador en un lugar fijo — presumiblemente, Pamplona-, se obligaría a los denunciadores a desplazarse y a incurrir en numerosos gastos, con lo que muchos se retraerían, además de ser también «muy reparable despojar sin conocida conveniencia a los alcaldes de la jurisdiccion privativa en primera instancia que les confiere el derecho y nuestras leyes, y aumentar Ministros sin necesidad», además del aumento de gastos que supondría para los pueblos el pago del salario y dietas del mismo en las visitas, de cuyo cumplimiento se encargaría la Diputación. Finalmente, el monarca aceptó la petición y se prescindió de la existencia de un juez conservador ${ }^{27}$ (Fortún, 1995, Libro 7, pp. 62-63).

Cuando Manuel de las Casas, desde San Sebastián, escribió en febrero de 1748 a la Diputación navarra enviándole la Real Ordenanza de 31 de enero de ese mismo año

\footnotetext{
$27 \quad$ Precisamente en el preámbulo de la ley 57 se hacía referencia a la ley 25 de 1567, la 10 y 44 de 1576 y 1680,28 de 1604 , la 57 de 1642 , la 16 de 1662.
} 
e informándole de que había sido nombrado inspector de Marina para los montes de Navarra y Guipúzcoa, por parte del marqués de la Ensenada, la Diputación se mostró dubitativa ${ }^{28}$. Si bien, en un principio, contestó sin mostrar queja alguna, en realidad no fue una aceptación tácita de la Real Ordenanza de 1748, puesto que todavía dos años después, el virrey preguntaba porque no era cumplida, respondiendo la Diputación que sometía a los naturales navarros a tribunales extraños y que en cuestión de montes bastaba con mantener la costumbre vigente hasta la época ${ }^{29}$. Fue entonces cuando el rey decidió tomar la iniciativa: en agosto de 1750, el marqués de Rocaverde fue enviado a Navarra para hacer observar la Real Ordenanza, con una instrucción precisa por parte del rey, para tratar con la Diputación la adaptación de las reglas al país, replantarlo y poblarlo de árboles. En caso de dificultades con las autoridades del reino, se le recomendaba acudir al virrey, para que interpusiese su autoridad. La instrucción preveía que, una vez aprobada la norma, haría visita a todos los montes y dispondría la cantidad y calidad de los plantíos a realizar, la erección de viveros, y pondría en práctica la Ordenanza, con las restricciones establecidas por la Diputación.

Para el interés del presente estudio, la instrucción se cerraba con una importante orden: terminada la visita, Rocaverde quedaría como juez de montes de Navarra, velando por el cumplimiento de la Real Ordenanza. La respuesta dada en septiembre por la Diputación fue aceptar los artículos del 1 al 14, aunque con la condición de modificar los artículos 1, 2, 3, 4 y 5, porque atribuían a los intendentes de Marina y sus visitadores autoridad y jurisdicción en lo relativo al plantío, incurriendo en contrafuero, ya que eran los tribunales del reino los únicos con autoridad en esa materia. Todos los artículos a partir del número 15, en los que se hablaba de la autoridad de los intendentes, visitadores y juez de montes eran incompatibles con los fueros de Navarra. Los capítulos 31 y 33 de la Real Ordenanza, sobre elección de lugares, y 27 y 29 , sobre precio de la madera, chocaban con las leyes 44, 45 y 48, libro 1, Titulo 4 de la Novísima Recopilación y con la 57 de las Cortes de Estella de 1724, por lo que consideraban que, aunque fuese para el Real Servicio, no se pudiesen cortar árboles sin anticipado aviso a los pueblos y tasándose con justo valor, permitiendo la llegada de contramaestres, como establecía el artículo 15 de la Real Ordenanza, para dar instrucción conveniente. Por su parte, el Consejo Real consideraba que la Real Ordenanza no era aceptada ni obtenía sobrecarta en Navarra por incurrir en numerosos contrafueros, sobre todo relacionados con la jurisdicción. Aunque el marqués de Rocaverde acudió a reunirse con la Diputación en septiembre y se avino a establecer las modificaciones solicitadas, esta todavía no había recibido respuesta en diciembre de $1752^{30}$.

AGN, Montes, legajo 1, carpeta 40.

AGN, Montes, legajo 1, carpeta 42.

AGN, Tribunales Reales, Archivo Secreto, tit. 4, fajo 2, n. 2. 
Sin embargo, siete años más tarde y a petición del propio monarca, fue cuando las Cortes promulgaron las Ordenanzas para la plantación y conservación de árboles, cuyo contenido se centraba básicamente en la creación de viveros, obligando a todos los pueblos y a los particulares a crear plantaciones de nuevos árboles. Efectivamente, por medio de una Real Orden de 2 de abril de 1757 se instruía al virrey para que en las siguientes Cortes de Navarra se tratase una serie de temas, entre los que en cuarto lugar estaba:

por ser de tanta importancia para la construcción de navíos, fabricas de templos y casas, alimento de las errerias y para consumo y uso común la plantación de arvoles de todas las especies, su conserbación y aumento, discurran los Tres Estados los medios de fomentar una especie de tanto interés, proponiendo además de las reglas establecidas en la ordenanza de montes, las que sean mas propias y acomodadas a este terreno y poniendo zeladores y jueces que sean responsables de este cuidado.

El 5 de mayo de 1757 se juntaron los Tres Estados y se resolvió pedir el contrafuero sobre el expediente de plantación de árboles que pendía en la Real Cámara. En septiembre de ese año, después de un largo debate sobre el mencionado cuarto punto, se resolvió nombrar tres miembros del brazo militar y tres de las universidades, para, teniendo presente la Real Ordenanza y las leyes del reino, formar borrador de las ordenanzas o reglamento correspondiente. La labor de la comisión terminó el 27 de septiembre, cuando presentó el borrador - aunque con posterioridad, durante el mes de octubre, el texto sufrió algunas modificaciones, pues se suprimió el capítulo final y se replicó el capítulo 14, referido a los gastos que causasen los viveros y plantación, de cuya obligación quedó eximida Pamplona, por ser plaza fuerte - y estableció la división del reino, según merindades, en dieciocho partidos, nombrando un inspector para cada uno — para los 9 primeros partidos se nombrarían nueve caballeros por el señor presidente del brazo militar y los 9 restantes por las universidades-, a fin de señalar los lugares más apropiados para las nuevas plantaciones, teniendo en cuenta las especies más adecuadas para cada zona (Providencias, 1781, pp. 1-43; Fortún, 1994, Libro 9, pp. 78, 82, 230, 239, 252, 259-260, 262-263, 273, 277, 292, 295-296).

El texto profundizaba en la forma de crear los viveros, cómo custodiarlos y las penas en que incurrirían los transgresores. En opinión de Iriarte Goñi (1991, p. 87), era una legislación fuertemente intervencionista, pero también muy ineficaz, puesto que no garantizaba mínimamente el cumplimiento de los objetivos. Curiosamente, el texto nada dice sobre los derechos de la Marina Real, lo que parece una aceptación al respecto. En realidad, las autoridades navarras asumieron la intervención de las autoridades navales a cambio de conservar su jurisdicción. Pero esta lectura también puede ser hecha a la inversa, es decir, la corona aceptó el mantenimiento de la juris- 
dicción de las instituciones navarras en materia de montes, a cambio de sus riquezas forestales para los reales arsenales. No se debe olvidar que la extracción de maderas desde la Navarra atlántica estuvo entre 1766 y 1782 en manos de la Real Compañía de Caracas, por lo que los montes navarros siguieron parcialmente la estela de los de Guipúzcoa y Vizcaya, con una solución intermedia.

No obstante, fue en la década de los años ochenta cuando las fricciones entre ambas instancias se hicieron más manifiestas, momento en el que se establecieron ciertas modificaciones en las ordenanzas a través de la ley 40 de las Cortes de 1780-1781, confirmadas por Real Orden de 24 de enero de 1781, por las que se prorrogaba la ley 54 de 1757 y la 32 de 1766 sobre plantación de árboles y conservación de montes y viveros, con una serie de aditamentos (Providencias, 1781, pp. 43-50): el cuarto aditamento establecía que los asentistas de madera debían comunicar su visita a la Diputación, para que esta controlase y supervisase los cortes que se fuesen a realizar y señalar precios, nombrando para ello ambas partes peritos; el quinto capítulo contemplaba la elección de un juez conservador de plantíos y viveros, debiendo ser uno de los ministros del Real Consejo, natural del reino, elegido por el virrey. El rey en su decreto, sin embargo, exigía que el juez conservador fuese un miembro de la corte o consejo, a elección del virrey, a quien las justicias locales debían enviar cualquier sumaria y autos. Dicho juez conservador mantenía independiente su jurisdicción en lo relativo a lo económico, pero en lo judicial y contencioso debía ser apelable al Consejo Real, como ocurría con los casos de contrabando.

A pesar de la aceptación del aditamento por parte del virrey, los abusos continuaron. En su réplica, las cortes insistían en que el juez conservador fuese del reino y en que se diese derecho de preferencia o tanteo a los originarios del reino frente a los extranjeros en las ventas de árboles. La corona, finalmente, aceptó el 16 de marzo que el juez conservador fuese un natural del reino. Posteriormente, se establecieron nuevas providencias en 1794 y 1818, y finalmente las Cortes de 1828 y 1829 establecieron la ley que rigió en adelante, hasta bien entrado el siglo XX; concretamente, el artículo 2 de dicha ley confería la dirección general gubernativa y económica de los arbolados y viveros al reino reunido en Cortes o a su Diputación, bajo cuya tutela se estableció una Junta de Montes, encargada de velar por los viveros, mientras que el ámbito contencioso, como ya hemos visto, quedaba en manos del juez conservador; en realidad, la ley — como en el resto de casos analizados - supuso un mayor intervencionismo de la Diputación, y un aumento de sus atribuciones en detrimento de las instituciones municipales $^{31}$ (Cuadernos de las Leyes, 1964, vol 1, pp. 620-625; Fortún, 1995, Libros 11-12, pp. 263-267; Iriarte Goñi, 1991, pp. 87-89; Providencias, 1781, pp. 51-62).

AGN, Montes, legajo 2, carpeta 50. 


\section{Conclusiones}

La publicación de las Ordenanzas de Montes de 1748 tuvo una respuesta individualizada y diferente en cada uno de los territorios vasco-navarros; y así fueron también las opciones y alternativas dadas por la corona. Ello se debió — más allá de las evidentes diferencias orográficas y climáticas - , sin duda, al diferente peso que, en cada coyuntura, tuvo cada uno de los territorios en las políticas navales de la mencionada corona. La provincia más privilegiada, tras un largo proceso, fue Guipúzcoa, gracias a la aportación de sus carpinteros en la construcción de la Real Armada y al impacto que la Real Compañía de Caracas tuvo en el surtimiento de los reales arsenales, tanto desde Guipúzcoa como desde Navarra. Precisamente, en la década de los años noventa, cuando el ingeniero José Muller se hallaba extrayendo las últimas maderas disponibles para el Ferrol desde los montes de la provincia, la corona confirmó su privativa y omnímoda jurisdicción, cerrando un proceso que había perdurado casi cuatro décadas.

Por su parte, Álava — que hay que recordar que no contaba con corregidor-, obtuvo algo similar, y si bien en la década de los años ochenta había quedado prácticamente marginada del proceso de extracción de maderas para el Departamento del Ferrol, ante el agotamiento de los montes de Asturias, Cantabria o norte de Burgos, volvió a aportar importantes cantidades de madera de roble, a cargo de cuya gestión estuvo el ingeniero Rafael Clavijo, lo que obligó a las instituciones alavesas a establecer un reglamento en 1784, aunque no sería definitivamente confirmado hasta 1793 , que concedía a dicha provincia la jurisdicción económica, gubernativa y, como en el caso de Guipúzcoa, contenciosa.

Vizcaya obtuvo en 1784, cuando se había convertido en un importante centro de construcción de paquebotes de correos para el transporte de maderas y otros avituallamientos hacia los reales arsenales, la confirmación de las ordenanzas redactadas en 1750 y modificadas en 1752, que le daban la jurisdicción económica y gubernativa, reservando para el corregidor la contenciosa. Por último, Navarra, uno de los principales centros de extracción de tablonería y mástiles del área cantábrico-pirenaica, sobre todo durante las décadas de 1750 a 1770, obtuvo en 1757 la confirmación de las ordenanzas, que reservaban a las autoridades territoriales la jurisdicción gubernativa y económica, desgajada de la contenciosa, que quedó en manos de un juez de montes que, tras arduas negociaciones, se consiguió fuese originario del reino (Aragón, 2001, pp. 112, 121, 158, 160, 203-205; 2017, pp. 41-54).

En todos los casos, las instituciones asamblearias y las diputaciones avanzaron en el ramo de montes en el fortalecimiento de sus atribuciones y dominio sobre el resto de instancias de poder, arrogándose jurisdicciones y competencias que no ostentaban hasta la fecha o que habían sido compartidas o desempeñadas por otras instituciones. 
No obstante, aquellas diputaciones que obtuvieron la jurisdicción contenciosa en materia de montes, se arrogaron los casos en los que las penas eran más sustanciosas — por encima de 1.000 reales en Guipúzcoa y de 20 ducados en Álava-, a fin de controlar las transgresiones más graves y establecer las penas más ejemplarizantes; lógico teniendo en cuenta la importancia de la riqueza forestal para la supervivencia de actividades claves, caso de la siderurgia o la construcción naval mercante, de las que dependía el comercio. En definitiva, el ramo de montes, experimentó los mismos procesos que otros apartados en los que las Provincias Exentas y el reino de Navarra, territorios forales durante el siglo XVIII, asistieron a la consolidación de su poder y dominio jurisdiccional sobre otras instancias de orden territorial; en gran parte, con la necesaria colaboración de la corona, que vio en estas instituciones un instrumento para obtener un mayor control efectivo y operativo sobre esos territorios (Portillo, 1991, pp. 614-618).

Como se ha podido comprobar, todo ello fue consecuencia de, por un lado, un intenso debate y conflicto interinstitucional, entre las instituciones territoriales y la corona. Ese debate se dio de forma individualizada por cada uno de los territorios; no obstante, las referencias a los otros territorios o el seguimiento de sus estrategias estuvieron siempre presentes. La corona hubo de «compartir» jurisdicciones a fin de no fracturar su relación con las élites y poderes locales, imprescindibles, por otro lado, en su plan para revitalizar la Real Armada y para el abastecimiento y movilización de los recursos forestales y humanos necesarios para ello. Ello mismo, le permitió, dentro de una lógica y dinámica dialécticas, construir «Estado», es decir, fortalecer su presencia y control en esos territorios. Precisamente esas elites e instituciones fueron sus principales agentes y valedores. Pero, por otro lado, el debate también se produjo a nivel interno, intrainstitucional, puesto que los intereses en cada uno de los territorios e instituciones asamblearias y representativas no eran unívocos. Esos mismos debates demuestran las tensiones y fricciones existentes en unos territorios e instituciones en los que existía una multiplicidad de situaciones, actividades e intereses, que hubieron de ir acoplándose al paso de los tiempos y circunstancias y amoldándose a los diferentes procesos por los que estaba pasando esa construcción del Estado. Los propios debates ayudaron a seguir unos caminos y a desechar otros, aunque las fricciones y enfrentamientos continuasen latentes, y a construir «territorio», dentro del «Estado». Más aún, nos atreveríamos a aseverar que sin esas dinámicas y sin el aporte de suministros forestales — y siderúrgicos — que permitieron, es imposible entender el desarrollo de la Armada española durante el siglo XVIII.

Las ordenanzas y capitulados específicos establecidos, además, estuvieron vigentes hasta bien entrado el siglo XIX, ya que la excepción en la aplicación de las medidas previstas en las Ordenanzas de Montes de 22 de diciembre de 1833 para el caso de 
las provincias vascas y Navarra, consignada en el artículo 212 del mismo, mantuvo en vigor las ordenanzas guipuzcoanas de 1749, vizcaínas de 1784, alavesas de 1794 y navarras de 1757 y 1828/29. Su definitiva modificación sería un proceso de largo recorrido, entre 1833 y 1900, al que hubieron de hacer frente las instituciones forales vascas y navarras, pero esa ya es otra historia (Garayo Urruela, 1992, pp. 125-165; Iriarte Goñi, 1991, pp. 89-104).

\section{AGRADECIMIENTOS}

Este trabajo se engloba en el Grupo de Investigación Consolidado del Sistema Universitario Vasco País Vasco, Europa y América: Vínculos y Relaciones Atlánticas (IT1241-19) y se enmarca en el proyecto I + D del Ministerio de Ciencia, Innovación y Universidades «Guerra, Estado y Sociedad. La movilización de recursos militares en la construcción de la Monarquía Española en el siglo XVIII» (PGC2018-096194-B-I00). 


\section{Bibliografía}

Alberdi Lonbide, Xabier (2012), Conflictos de intereses en la economía marítima guipuzcoana, siglos XVI-XVIII, Bilbao, Universidad del País Vasco.

Aragón RuAno, Álvaro (2001a), El bosque guipuzcoano durante la Edad Moderna: aprovechamiento, ordenamiento legal y conflictividad, San Sebastián, Sociedad de Ciencias Aranzadi.

Aragón Ruano, Álvaro (2001b), «Conflictos entre el Corregidor y la Provincia de Guipúzcoa por la jurisdicción sobre los bosques durante el siglo XVIII: lo excepcional del caso guipuzcoano», Vasconia, 31, pp. 45-65.

Aragón Ruano, Álvaro (2013), «En pos de la sostenibilidad. Cambios en la gestión forestal guipuzcoana durante la Edad Moderna», Cuadernos de la Sociedad Española de Ciencias Forestales, 38, pp. 43-48. Doi: https://doi.org/10.31167/ csef.v0i38.10295

Aragón Ruano, Álvaro (2017), «Mar de árboles, vorágine de jurisdicciones. La complicada relación entre la Real Armada española y los bosques del Pirineo occidental peninsular en el siglo XVIII», en Varela Gomes, Rosa y Trápaga Monchet, Koldo (eds.), Árvores, barcos e homens na Península Ibérica (Séculos XVI-XVIII), Lisboa, Instituto de Arqueologia e Paleociencias - Instituto de História Contemporánea, pp. 41-54.

Aranda y Antón, Gaspar (1990), Los bosques flotantes. Historia de un roble del siglo XVIII, Madrid, ICONA.

BAUER MANDERCHEID, Enrich (1980), Los montes de España en la Historia, Madrid, Ministerio de Agricultura.

Bilbao BilbaO, Luis María (1996), «La economía de la provincia de Álava en la etapa foral, 1458-1876», en Actas de las Juntas Generales de Álava, Tomo V (1556-1565), Vitoria, Juntas Generales de Álava, pp. 17-159.

CARRIÓN ARREGUI, Ignacio María (1991), La siderurgia guipuzcoana en el siglo XVIII, Bilbao, UPV/EHU - Kutxa.

Cundernos de las Leyes y Agravios reparados por los Tres Estados del Reino de Navarra, vol 1, Pamplona, Gobierno de Navarra, 1964.

CUADERNo de Leyes y ordenanzas, con que se gobierna esta muy noble y muy leal provincia de Álava y diferentes privilegios y cédulas de su magestad que van puestos en el índice, Vitoria, Agapito Mantell, 1825.

ForTún PÉREZ DE CiRIZA, Luis Javier (dir.), Actas de las Cortes de Navarra (1530-1829), Libro 9 (1757), Pamplona, Parlamento de Navarra, 1994, 
Fortún PÉrez de Ciriza, Luis Javier (dir.), Actas de las Cortes de Navarra (1530-1829), Libro 11 y 12 (1780-1781), Pamplona, Parlamento, 1995.

Gárate Ojanguren, Montserrat (1990), La Real Compañia Guipuzcoana de Caracas, San Sebastián, Sociedad Guipuzcoana de Ediciones y Publicaciones.

Garayo Urruela, Jesús María (1991), «Las comunidades de montes de Álava», Narria: Estudios de artes y costumbres populares, 53-54, pp. 13-22.

Garayo Urruela, Jesús María (1992), «Los montes del País Vasco (1833-1935», Agricultura y sociedad, 65, pp. 121-174.

Gorosabel, Pablo (1899-1901), Noticia de las Cosas Memorables de Guipúzcoa, Tolosa, López, 6 vol.

Guerra Velasco, Juan Carlos (1999), «Apuntes para un balance de la política de montes y plantíos en el Antiguo Régimen: las ordenanzas de 1748 y su aplicación en Castilla», Cuadernos de la Sociedad Española de Ciencias Forestales, 8, pp. 59-66. Doi: https://doi.org/10.31167/csef.v0i8.9174

IRIARTE GoÑI, Iñaki (1991), «La legislación de los montes públicos en Navarra de finales del Antiguo Régimen a las primeras décadas del siglo XX», Gerónimo de Ustáriz, 5, pp. 85-106.

Madrazo García de Lomana, Gonzalo (2003), «Las certificaciones de montes y plantíos en la vertiente segoviana de la sierra de Guadarrama», Cuadernos de la Sociedad Española de Ciencias Forestales, 16, pp. 56-60. Doi: https://doi. org/10.31167/csef.v0i16.9349

Martínez González, Alfredo José (2014), «La elaboración de la Ordenanza de Montes de Marina, de 31 de enero de 1748, base dela política oceánica de la monarquía española durante el siglo XVIII», Anuario de Estudios Americanos, 71, 2, pp. 571-602. Doi: 10.3989/aeamer.2014.2.07

Martínez GonzÁlez, Alfredo José (2015a), «Masas forestales para las Armadas: las áreas jurisdiccionales de montes y plantíos (siglo XVI-XVIII)»,Naveg@mérica. Revista electrónica editada por la Asociación Española de Americanistas, 14.

Martínez González, Alfredo José (2015b), Las Superintendencias de Montes y Plantíos (1574-1748). Derecho y política forestal para las armadas en la Edad Moderna, Valencia, Tirant lo Blanch.

Martínez Rueda, Fernando (2008), «Las Juntas de Avellaneda en el Antiguo Régimen», Iura Vasconiae, 5, pp. 221-254.

(1975) Novisima Recopilación de las leyes de España, 1805 (facsimil), Madrid, Boletín Oficial del Estado.

Odriozola Oyarbide, Lourdes (1997), La construcción naval en Gipuzkoa, siglo XVIII, San Sebastián, Diputación Foral de Gipuzkoa. 
Pezzi CRISTÓBAL, Pilar (2001), «Proteger para producir. La política forestal de los Borbones españoles», Baetica. Estudios de Arte, Geografía e Historia, 23, pp. 583-595.

Portillo VAldés, José María (1991), Monarquía y gobierno provincial: poder y constitución en las provincias vascas (1760-1808), Madrid, Centro de Estudios Políticos y Constitucionales.

Porres MAriJuÁn, Rosario (2007), «Un impuesto singular: el diezmo-señor y la sal en Añana: siglos XVI-XIX», Hispania. Revista Española de Historia, LXVII, 225, pp. 173-208. Doi: https://doi.org/10.3989/hispania.2007.v67.i225.40

(1781), Providencias establecidas para la conservación de montes y nuevos plantios, su dirección, y gobierno, Pamplona, Joaquín Domingo.

Quintero GonzÁlez, José (2004), La Carraca. El primer arsenal ilustrado español (1717-1776), Madrid, Ministerio de Defensa.

(1718) Registro de la Junta General, que esta Muy Noble, y Muy Leal Provincia de Guipúzcoa ha celebrado en la Noble, y Leal Villa de Elgoybar, este año de 1718, San Sebastián, Bartolomé Riesgo y Montero.

(1738) Registro de la Junta General, que esta Muy Noble, y Muy Leal Provincia de Guipúzcoa ha celebrado en la Noble, y Leal Villa de Deba, este año de 1738, San Sebastián, Bartolomé Riesgo y Montero.

Rey Castelao, Ofelia (1995), Montes y politica forestal en la Galicia del Antiguo Régimen, Santiago de Compostela, Universidad de Santiago de Compostela.

Rey CASTElaO, Ofelia (2004), «Montes, bosques y zonas comunales: aprovechamientos agrícola-ganaderos, forestales y cinegéticos», en Aranda Pérez, Francisco José (coord.), El mundo rural en la España Moderna, Cuenca, Universidad de Castilla-La Mancha, pp. 907-964.

Rodríguez Fernández, José (2014), Agua, poder y sociedad en el mundo urbano alavés bajomedieval y moderno, Vitoria, UPV/EHU [Tesis doctoral].

Torres SÁnchez, Rafael (2013), «Administración o asiento. La política estatal de suministros militares en la Monarquía española del siglo XVIII», Studia Histórica, Historia Moderna, 35, pp. 159-199. Doi: http://dx.doi.org/10.14201/ shhmo201335159199

URIARTE AYO, Rafael (1988), Estructura, desarrollo y crisis de la siderurgia tradicional vizcaína (1700-1840), Bilbao, UPV/EHU.

URTEAGA, Luis (1987), La tierra esquilmada. Las ideas sobre la conservación de la naturaleza en la cultura española del siglo XVIII, Madrid, Serbal/CSIC.

VILlAREAl DE BÉRrIz, Bernardo (1736), Máquinas hydráulicas de molinos y herrerías, y govierno de los árboles y montes de Vizcaya, Madrid, Antonio Marín. 
162 Álvaro

Aragón RuAnO

WING, John T. (2015), Root of Empire. Forest and State Power in Early Modern Spain, c. 1500-1750), Leiden-Boston, Brill.

Zabala Uriarte, Aingeru (1994), Mundo urbano y actividad mercantil, Bilbao 1700-1810, Bilbao, Bilbao Bizkaia Kutxa. 